\title{
DÜBLIN
}

Technological University Dublin

ARROW@TU Dublin

Articles

National Institute for Transport and Logistics

2011-07-01

\section{Towards a Unified Definition of Supply Chain Management}

\author{
Edward Sweeney \\ Technological University Dublin, edward.sweeney@tudublin.ie
}

Follow this and additional works at: https://arrow.tudublin.ie/nitlart

Part of the Business Administration, Management, and Operations Commons, Civil and Environmental Engineering Commons, and the Other Operations Research, Systems Engineering and Industrial Engineering Commons

\section{Recommended Citation}

Sweeney, E. (2011)Towards a Unified Definition of Supply Chain Management. International Journal of Applied Logistics, vol. 2 Issue 3, pp. 30-48. July-September.

This Article is brought to you for free and open access by the National Institute for Transport and Logistics at ARROW@TU Dublin. It has been accepted for inclusion in Articles by an authorized administrator of ARROW@TU Dublin. For more information, please contact arrow.admin@tudublin.ie, aisling.coyne@tudublin.ie, gerard.connolly@tudublin.ie.

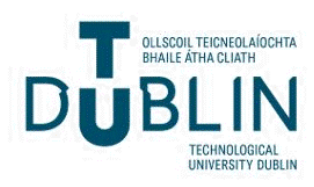




\section{INTERNATIONAL JOURNAL OF APPLIED}

\section{Logistics}

July-September 2011, Vol. 2, No. 3

\section{Table of Contents}

\section{Research Articles}

1 A Closed-Loop Logistics Model for Green Supply Chain Management

A. H. Basiri, K. N. Toosi University of Technology, Iran

A. Shemshadi, K. N. Toosi University of Technology, Iran

M. J. Tarokh, K. N. Toosi University of Technology, Iran

16 Utilizing SMS/3G Networks for Better and Reliable Communications Between Yard Cranes and Server

C. D. Cheng, NDI Automation Pte. Ltd., Singapore

C. C. Ko, National University of Singapore, Singapore

W. J. Huang, National University of Singapore, Singapore

30 Towards a Unified Definition of Supply Chain Management: The Four Fundamentals Edward Sweeney, Dublin Institute of Technology, Ireland

49 Process Analysis of Knowledge Production Raafat G. Saadé, Concordia University, Canada Ali Ahmed, Concordia University, Canada 


\title{
Towards a Unified Definition of Supply Chain Management: The Four Fundamentals
}

\author{
Edward Sweeney, Dublin Institute of Technology, Ireland
}

\begin{abstract}
A wide range of definitions of supply chain management (SCM) have been developed over the last three decades. The philosophy of SCM is based firmly on a recognition that it is only by working in a more integrated manner that competitive advantage can be maximised. However, for this to become a reality the development of common definitions and understandings between supply chain partners is a critical success factor. The corollary of this is that a lack of definitional consistency and a common understanding is an inhibitor to the successful adoption of SCM thinking in practice. This paper reviews a number of definitions of SCM, as well as discussions and analyses of such definitions. This leads to the central point posited in the paper - the need for a 'unified definition'. Such a definitional construct, labelled the Four Fundamentals of SCM, is proposed with the core of the paper providing a narrative description of this construct based on a wide range of literature.
\end{abstract}

Keywords: $\quad$ Construct, Definitions, Fundamentals, Practitioner, Supply Chain Management (SCM)

\section{INTRODUCTION}

Since its introduction by management consultants in the early 1980s (Oliver \& Webber, 1982), a plethora of supply chain management (SCM) definitions have been developed. There is evidence of differences in emphasis and approach between different industrial sectors, geographical areas and functional backgrounds (Sweeney, 2007). Furthermore, a variety of associated terminologies have also been developed which has added to the complexity. As noted by Ross (1998), this can limit management's understanding of the SCM concept and

DOI: $10.4018 /$ jal.2011070103 the practical effectiveness of its application. Nonetheless, SCM has risen to prominence in recent years in both academic and commercial circles. However, there is still no universally accepted definition of what SCM is (and, indeed, is not). As pointed out in a widely cited article by Mentzer et al. (2001):

Despite the popularity of the term Supply Chain Management, both in academia and practice, there remains considerable confusion as to its meaning. Some authors describe SCM in operations terms involving flow of products and materials, some view it as a management philosophy, and some view it as a management process (p. 2). 
Given that the notion of intra-firm and inter-firm integration and alignment is central to $\mathrm{SCM}$, there is increasing recognition among scholars and practitioners of the need for common definitions. For example, Mentzer et al. (2001) made the point that without a clear understanding of SCM, wide application of $\mathrm{SCM}$ in practice cannot be expected. From a research perspective, there are clear potential benefits associated with viewing the large body extant SCM literature, as well as emerging research findings, through the prism of a unified definitional construct.

Following this introduction, the next section reviews a number of widely cited definitions of SCM. This leads to the central point posited by the author in this paper - the need for a 'unified definition'. Such a definitional construct, labelled the Four Fundamentals of $\mathrm{SCM}$, is proposed by the author with the core of the paper providing a narrative description of this construct based on a wide range of literature. Finally, some suggestions for further work are identified and some conclusions drawn.

\section{SCM DEFINITIONS}

Given the large number of definitions that have been developed over the years an exhaustive list and/or detailed descriptions of existing definitions of SCM is beyond the scope of this paper. However, this section provides an overview of some of the widely cited definitions, as well as of discussions and analyses of such definitions, and draws some conclusions from a synthesis of these. The selected definitions have also been chosen to be representative of the themes and concepts expressed across the wider body of definitions.

\section{Defining SCM (Mentzer et al., 2001)}

Mentzer et al. (2001) provide a comprehensive overview of the more important of these definitions and, based on their analysis, provide a definition of their own. From this representative sample of SCM definitions, Mentzer et al. suggested that three definition categories can be identified. Firstly, many authors define SCM as a management philosophy. In this context, SCM adopts a systems approach to viewing the supply chain as a whole, from the supplier to the ultimate customer. A chain-wide collaborative approach, driven by a strong customer focus, aims to synchronise intra-firm and inter-firm capabilities. Secondly, many authors consider SCM as a set of activities to implement a management philosophy. Seven activities are proposed, based on the earlier research, which appear necessary in the successful implementation of the philosophy:

1. Integrated behaviour in customer and supplier firms.

2. Mutually sharing information.

3. Mutually sharing risks and rewards.

4. Cooperation among supply chain members.

5. The same goal and the same focus on serving customers.

6. Integration of processes.

7. Partnerships to build and maintain longterm relationships.

Each of these activities relates to various aspects of inter-firm relationship managements. Thirdly, Mentzer et al. (2001) note that many authors have focused on SCM as a set of management processes. In this context, a process is defined as, "a specific ordering of work activities across time and place, with a beginning, an end, clearly defined inputs and outputs, and a structure for action" (p. 10). This is very much in line with business process reengineering (BPR) thinking, as championed by Michael Hammer (Hammer \& Champy 1993). In essence, business processes take inputs and create outputs, and these outputs should be of value to a customer. Finally, the definition proposed by Mentzer et al. (2001) is:

the systemic, strategic coordination of the traditional business functions and the tactics across these business functions within a particular company and across businesses within the supply chain, for the purposes of improving the 
long-term performance of the individual companies and the supply chain as a whole (p. 18).

\section{SCM: A STRATEGIC PERSPECTIVE (BECHTEL \& JAYARAM, 1997)}

Bechtel and Jayaram (1997) presented a comprehensive review of definitions of both 'supply chain' and 'supply chain management' which appeared between the early 1980s and the mid 1990 s. Based on this, they synthesised existing definitions into five 'supply chain schools of thought'.

The schools of thought are:

1. FunctionalChain Awareness School, which recognises that a chain of functional areas exists across an organisation.

2. Linkage/Logistics School, which goes beyond the chain awareness school by recognising that there is a chain from suppliers to end users and begins to address material flows through this chain.

3. Information School, which emphasises the flow of information between supply chain members.

4. Integration/Process School, which focuses on integrating supply chain areas into a system - defined as a set of processes which adds value.

5. Future, based on a demand driven seamless pipeline emphasising relations as well as transactions.

The work of Bechtel and Jayaram (1997), in identifying these schools of thought, provides some noteworthy insights into the essence of SCM. Firstly, there is a strong emphasis on the concept of integration and an associated emphasis on relational as opposed to purely transactional issues. They specifically note that "the SCM concept is becoming closely tied to the concepts of partnerships, strategic alliances, and other cooperative relationships with supply chain members" (p. 18). Secondly, they question the use of the word 'supply' in SCM as it implies a traditional push orientation. As SCM is driven by an understanding of customer requirements, they suggest that "a better term might be "seamless demand pipeline" (p. 18).

\section{CSCMP Definition (CSCMP, 2010)}

The US-based Council of Supply Chain Management Professionals (CSCMP) defines SCM as follows:

Supply chain management encompasses the planning and management of all activities involved in sourcing and procurement, conversion, and all logistics management activities. Importantly, it also includes coordination and collaboration with channel partners, which can be suppliers, intermediaries, third-party service providers, and customers. In essence, SCM integrates supply and demand management within and across companies.

The phrase 'logistics management' is incorporated into this definition. It defines this as:

That part of supply chain management that plans, implements, and controls the efficient, effectiveforward and reverseflow and storage of goods, services and related information between the point of origin and the point of consumption in order to meet customers' requirements.

The specific emphasis on "reverse flows" is a recognition of the increasingly importance of reverse logistics. In discussing boundaries and relationships, CSCMP goes on to state that SCM is an "integrating function", which "drives coordination of processes and activities with and across marketing, sales, product design, finance, and information technology". The approach represented by this definition reiterates some of the earlier points and again has a strong emphasis on internal and external coordination and collaboration. However, the final part of the SCM definition - i.e., "In essence, SCM integrates supply and demand management within and across companies" - provides a useful conceptual view of SCM and is noteworthy for 
its simplicity, with its focus on synchronisation of supply and demand.

\section{TOWARDS A UNIFIED DEFINITION OF SCM: THE FOUR FUNDAMENTALS}

Based on a synthesis of these definitions, a number of points are critically important. Firstly, the very fact that many SCM definitions exist may, of itself, limit management's understanding of the SCM concept and the practical effectiveness its application (Ross 1998). Furthermore, a range of - often quite complex - SCM language and terminology has evolved over the years. Given that there are many bodies of literature associated with SCM this should not come as a major surprise. Mentzer et al. (2001, pp. 2-3) refer to "confusion", "ambiguity" and "a need to examine the phenomena of SCM more closely to define the term and concept"; Lambert (2004) noted that there is a great deal of confusion regarding exactly what SCM involves; Croom et al. (2000, p. 68) note that despite the existence of SCM since the early 1980s, "conceptually the management of supply chains is not particularly well understood" and go on to highlight the necessity for clear definitional constructs; Burgess et al. (2006, p. 704) observe that, "For the term SCM there appears to be little consensus on its definition"; Kathawala and Abdou (2003, p. 141) conclude that SCM "has been poorly defined and there is a high degree of variability in people's minds about what is meant".

Other scholars, including New (1995) and Saunders (1995) contend that there is a confusing profusion of overlapping terminologies and meanings. For example, Tan (2001) notes that:

The literature is replete with buzzwords such as: integrated purchasing strategy, integrated logistics, supplier integration, buyer/supplier partnerships, supply base management, strategic supplier alliances, supply chain synchronization and supply chain management (p. 41).
He went on to suggest that supply chain management is a "widely used (and abused) term" (p. 39). Croom et al. (2000) also note that many labels can be found referring to supply chain and to practices for SCM, including: integrated purchasing strategy, supplier integration, buyer/supplier partnership, supply base management, strategic supplier alliances, supply chain synchronisation, network supply chain, value-added chain, lean chain approach, supply pipeline management, supply network and value stream. Cousins et al. (2006) also note the use of terms such as pipeline management, network sourcing, demand management and value stream management.

Furthermore, many of the SCM definitions in the literature attempt to provide short (often single-sentence) definitions (CSCMP, 2009; Mentzer et al., 2001). In the author's view, the results are, almost inevitably, achievements in verbal and linguistic dexterity rather than definitions which are likely to add clarity from an SCM application perspective.

The Four Fundamentals represent an attempt to concisely, yet comprehensively, define the essence of SCM. It is aimed primarily at a practitioner audience and aims to bring clarity and understanding to the issue. The avoidance of jargon and complex language is an element of this. It takes into account the guidance provided by New (1997):

On the one hand, too tight a definition of the supply chain concept artificially closes off productive avenues of development. On the other hand, too loose a definition allows the label to collapse into an amorphous study of everything (p. 16).

The Four Fundamentals seek to describe the main constituent elements of SCM, as well as positioning SCM in the overall corporate strategic framework. Furthermore, its aims to provide a definition which is intelligible; irrespective of the functional background, business sector, or geographical location of the 
practitioner. Finally, the Four Fundamentals need to be relevant to supply chain professionals irrespective of their level of experience and/or seniority in industry. They relate to:

\section{Setting SCM objectives.}

2. SCM philosophy.

3. Managing the flows.

4. Supply chain relationships.

The following sections describe each of the fundamentals in turn.

\section{FUNDAMENTAL ONE: SETTING SCM OBJECTIVES}

\section{The Role of Objectives}

The concept of management by objectives (MBO) has been written about for many years and continues to attract attention. The basic concept of $\mathrm{MBO}$ is that agreed objectives form the basis of the planning process. Setting objectives is of crucial importance for any planning activity and is central to the successful creation and implementation of any plan for several reasons, including the following:

- It focuses the attention of planners on the main targets to be achieved.

- It provides a sense of direction to those creating and implementing the plan.

- It provides a basis for post hoc evaluation of the plan.

For these and other reasons, the creation of business objectives continues to play a key role in lexicon of management training and education.

From an SCM perspective, the key objectives are:

- To meet or exceed the required or demanded customer service levels in targeted markets/ segments.

- To optimise total supply chain investment and cost.
This service/cost approach has long been regarded as central to SCM (Christopher, 2005).

\section{Customer Service}

Customer service has long been recognised as an integral component of a firm's marketing strategy to increase sales and profits. Furthermore, customer service is becoming a key source of differentiation or an order winning criterion in many sectors (Christopher, 2005). In many sectors the importance of customer service relative to product quality (now largely an order qualifier) and price (largely determined by the dynamics of supply and demand in the market and subject to downward pressure in many sectors) has increased (Sweeney, 2007). In other words, the importance of customer service as an element of the overall marketing mix of organisations has increased.

The key to the role of customer service in SCM lies in: (1) understanding customers' needs and requirements in targeted markets/ segments; and then, (2) meeting (or exceeding) these needs. In assessing prior research, Sterling and Lambert (1989) concluded that many of the past studies in this area narrowly defined customer service and failed to measure it from a customer's point of view. Table 1 shows the suggested constituent elements of customer service. Most of these overlap with the elements suggested by Grant (2004) based on the original work of La Londe and Zinszer (1976).

These elements form the basis of both the external and the internal audit processes. Armed with the information yielded by these, companies can then develop market-driven customer service strategies, which deliver the level of service customers actually want and are willing to pay for, and exploit company strengths and competitor weaknesses.

It is not just about improving service as the title of Christopher (1992) suggests. Rather the objective needs to be, as pointed out earlier: to meet or exceed the required or demanded customer service level in targeted markets/ segments. This may result in a requirement to improve service but, as pointed out by NITL 
Table 1. Elements of customer service

\begin{tabular}{|l|}
\hline \multicolumn{1}{|c|}{ Customer Service Elements } \\
\hline • Product Availability (Can orders be filled) \\
\hline • Length of Order Cycle Time (Time it takes from order to delivery, usually counted in days) \\
\hline • Consistency of Order Cycle Time (Always the same length of time from order to delivery) \\
\hline • Invoice/Billing Procedures/Accuracy \\
\hline • Information Request Responsiveness (How fast does company respond) \\
\hline • Flexibility in Resolving Problems \\
\hline • Distance to Suppliers Warehouse \\
\hline • Special Customer Requests \\
\hline • Frequency of Damaged Goods (Do products get damaged on the way to the customer?) \\
\hline • Quality of Order Department \\
\hline • On-time Delivery \\
\hline
\end{tabular}

(2001, p. 3) for example, "it is quite common to find companies incurring significant costs to provide a speedy response to customers ... customers often indicate that speed is not the issue". In other words, companies may be over-servicing customers in certain ways (e.g. length of order cycle time), while failing to meet their needs in other, more critical, ways (e.g. consistency of order cycle time). The key is to recognise that understanding customer service requirements is the starting point in the supply chain design process. In other words, as shown in Figure 1, a market-driven customer service strategy - based on clearly understood customer requirements - sets the specification for integrated SCM. The title of the paper by Korpela et al. (2001) 'Customer Service Based Design of the Supply Chain' captures this approach very effectively.

\section{Total Supply Chain Investment and Costs}

A significant amount of the cost base of companies is in the supply chain and a key objective is to optimise this (and all other) expenditure. The emphasis must be on total supply chain costs. The key issue is that a reduction in expenditure in one part of the supply chain (e.g. purchasing) may result in an increase elsewhere (e.g. inventory holding costs). In line with overall SCM philosophy it is important to take a supply chain wide view and to recognise the inevitable trade-offs that need to be addressed. The trade-off approach to supply chain costing has been a feature of the literature for many years. Direct product profitability (DPP) represents an attempt to determine the costs of moving products through the entire supply chain. As the name suggests, DPP is essentially a technique for identifying the profit contribution of individual products by taking into account the specific supply chain costs incurred by particular items. However, traditional DPP models ignored overhead and administrative costs which resulted in inaccuracies in terms of determining real total costs. The development of activity-based costing (ABC) in the 1980s was an attempt to assign overhead costs more accurately within organisations. However, as noted by La Londe and Pohlen (1996), despite the advantages of $\mathrm{ABC}$, the methodology does not provide a satisfactory solution to these SCM challenges.

The total cost of ownership (TCO) approach addresses some of these weaknesses. This approach recognises that purchase price represents only a portion of the total cost of acquiring an item. It seeks to identify total acquisition price by including the costs of purchasing, stock 
Figure 1. Customer service in integrated SCM performance specification

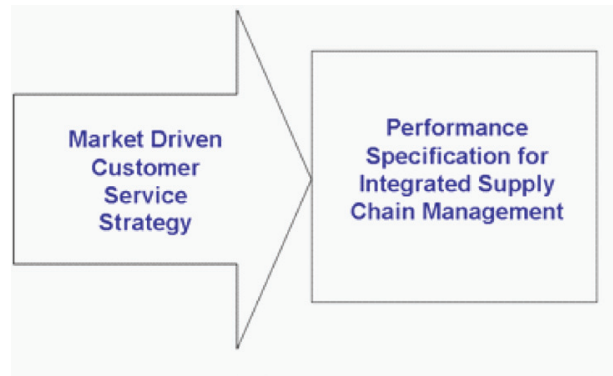

holding, poor quality and delivery failure. La Londe and Pohlen (1996) provide a useful supply chain costing model. Their six-step methodology incorporates elements of trade-off analysis, DPP and ABC.

The foregoing relates to supply chain costs. Similar logic can be applied to the issue of investment in supply chain capability. In broad terms, such investment aims to improve service performance and/or reduce costs. As noted by New (1995) the expenditure involved can be significant and needs to be subject to the usual investment appraisal processes to assess its value to the firm. Finally, it should be noted that the objective is not just about reducing costs as the title of Christopher (1992) suggests. Rather the objective needs to be, as pointed out earlier: to optimise total supply chain investment and cost. For example, it may be necessary to commit investment to supply chain improvement and/or to increase operating costs to meet (or exceed) customer service requirements. In any case, it is important that total supply chain investment and cost is assessed as fully and as accurately as possible. An understanding of the current situation provides a key input to the supply chain design process. It could also be argued that the effectiveness of SCM implementation is assessed by measuring its impact on financial performance, as shown in Figure 2.

\section{The Service/Cost Conundrum}

The foregoing raises the issue of how both customer service and financial improvements can be achieved simultaneously - i.e., the ser- vice/cost conundrum. Conceptually, customer service improvements and cost reductions might appear to be mutually exclusive; that is, service improvements require investment in supply chain capability or increases in supply chain operating costs, and reductions in expenditure causes service levels to be reduced. The objective is to affect a balance between what are often seen as conflicting goals of high customer service and low unit cost. Two simple equations (Christopher \& Towill, 2000) provide a useful illustration of this issue.

1. Supply chain total PDP costs $=$ Physical PDP costs + Marketability costs.

PDP is product delivery process. 'Physical costs' include all production, distribution and storage costs. 'Marketability costs' include all obsolescence and stock-out costs.

2. Total value $=($ Quality $\times$ Service level $) /$ (Costs $\times$ Lead time).

The first equation indicates that costs associated with a failure to meet customer requirements are just as much a part of total cost as the, often more easily measurable, physical costs. To optimise total cost, therefore, customer service level demands need to be met and physical costs need to be optimised. As pointed out by Christopher and Towill (2000) the second equation is particularly helpful as it emphasises the futility of improving one performance measure at the expense of another. Furthermore, the equation re-introduces the 
Figure 2. Improved financial performance measures the effectiveness of SCM

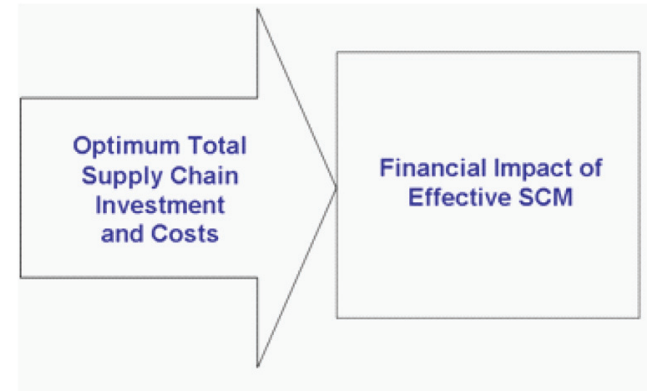

concept of value. In the author's view this is the key to addressing the service/cost conundrum. The creation of value requires that all four elements in the equation are tackled simultaneously.

\section{Fundamental One: Summary and Some Concluding Points}

Fundamental One recognises the importance of objectives and sets out clearly the two generic SCM objectives. Any attempt at improving supply chain capability needs to be based on improving performance in these two areas. Understanding customer requirements in the marketplace and current supply chain cost elements and drivers then becomes the starting point for the supply chain improvement/ reengineering process. As shown in Figure 1, the development of a market-driven customer service strategy sets the specification for SCM. Improved financial performance measures the effectiveness of SCM(Figure 2). Figure 3 shows how achievement of the two objectives combines to create competitive advantage through integrated SCM.

Furthermore, it should be noted that there will inevitably be target markets (or segments or individual customers) which a company would like to service and where the cost of doing so provides the opportunity to capture profitable market share. Similarly, there will inevitably be others where the cost of doing so is prohibitive. This logic enables market segmentation and targeting to be based on 'cost- to-serve' models. In this way, SCM and the setting of clear SCM objectives specifically, becomes a key element of corporate marketing planning.

Finally, it is worth returning to the concept of value, which could be regarded as linking the cost/investment and customer service objectives. As noted by Lambert and Cooper (2000) "the objective of SCM is to create the most value, not simply for the company, but for the whole supply chain network including the end customer" (p. 82).

\section{FUNDAMENTAL TWO: SCM PHILOSOPHY}

\section{Supply Chain Integration (SCI)}

It is evident that the concept of integration lies at the heart of SCM philosophy (Christopher, 1992; New, 1997; Lambert, 2004). Storey et al. (2006) in their discussion of the interlocking ideas and propositions of SCM declare that, "the central underpinning ideas relate to alignment and integration" (p. 758). Perhaps most tellingly, Pagell (2004) states that "in its essence the entire concept of SCM is really predicated on integration" (p. 460). If, as Mentzer et al. (2001) suggested, SCM can be regarded as a management philosophy then this philosophy is concerned first and foremost with integration. The widely cited work of Bowersox and his collaborators at Michican State University (Bowersox et al., 2000), which describes a 
Figure 3. Achieving competitive advantage through integrated SCM

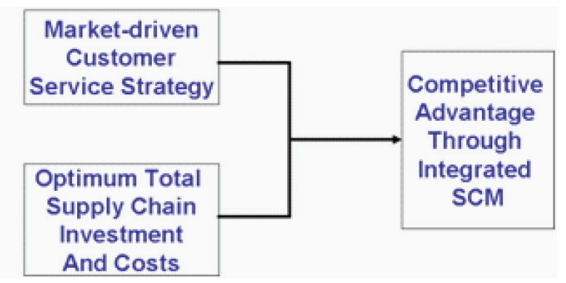

framework of six competencies (the Supply Chain 2000Framework) that lead to world class performance in logistics and SCM, supports this view. These competencies, grouped into three areas (operational, planning and relational), are all concerned with integration. Other approaches, notably the SCOR model of the USbased Supply Chain Council (Supply Chain Council, 2010) and the value chain concept (Porter, 1985), also emphasise the concept of different processes in the supply chain operating in an integrated manner to create value.

The work of Fawcett and Magnan (2002) identified four levels of integration in practice:

1. Internal cross-functional integration.

2. Backward integration with valued first-tier suppliers.

3. Forward integration with valued first-tier customers.

4. Complete backward and forward integration ('from the supplier's supplier to the customer's customer').

Furthermore, Harland et al. (1999) classifies research in this area according to the level of integration between supply chain activities. The four levels are:

1. Internal level, which considers only on those activities which are entirely internal to the focal company.

2. Dyadic level, which considers single twoparty relationships (between, for example, supplier and manufacturer or manufacturer and distributor/retailer).
3. Chain level, which encompasses a set of dyadic relationships including a supplier, a supplier's supplier, a customer and a customer's customer.

4. Network level, which concerns a wider network of operations.

In each of these cases, the first level relates to integration of activities and processes which are carried out within a single organisation (i.e. internal or micro- or intra-firm supply chain integration). The others describe varying degrees of integration of activities which span the boundaries of organisations (i.e. external or macro- or inter-firm supply chain integration), with the last one of Fawcett and Magnan (2002) often being viewed as the theoretical ideal. The following sections discuss internal and external integration in more detail.

\section{Internal Chain Integration}

The phrase 'internal supply chain' has appeared in the literature to describe worked aimed at breaking down the barriers between functions within organisations. To establish a framework for describing the key functions of a typical internal supply chain, New's comment (1997, p. 17) that SCM "revolves around the buying, making, moving and selling of 'stuff' "' is quite instructive. It is in line with the 'buy-makemove-sell' model of product supply chains. For the purposes of this section the author has added a fifth element, namely the 'store' activity. This has been done to ensure that all activities associated with the design and management of warehouses and other storage locations is given 
due recognition in the framework. Warehouse management has long been regarded as an integral element of the logistics activity of firms and a significant amount of specialist knowledge and expertise in this area has been developed over the years. Essentially, 'move' has been disaggregated into separate 'move' and 'store' elements, reflecting the specific characteristics of each of these activities.

Most businesses - certainly manufacturingbased business - can be described in terms of the five functions: buy, make, store, move and sell. This is what is referred to as the internal (or micro- or intra-firm) supply chain as shown in Figure 4. It is important to emphasise that there is no significance in the order in which these functions are set out. For example, in most supply chain one would expect logistics operations (i.e. 'move' and 'store') to appear between 'buy' and 'make' (i.e. as well as between 'make' and 'sell').

Traditionally these functions have often been measured, and therefore managed, in isolation, often working at cross purposes. As succinctly noted by Storey et al. (2006) this traditional approach is analogous to a relay race with responsibility being passed from one function to another. SCM means thinking beyond the established boundaries, strengthening the linkages between the functions, and finding ways for them to pull together. A recognition that the "whole is greater than the sum of the parts' calls for more effective integration between purchasing and procurement (buy), production planning and control (make), warehouse management (store), transport management (move) and customer relationship management (sell),

This shift, away from a functional orientation towards a more company-wide focus, is in line with the early stages of the various models of SCM historical evolution introduced previously. It is also analogous to the 'supply chain orientation' (SCO) approach of Mentzer et al. (2001) in the sense that SCO at firm level, as manifested in high levels of internal integration, could be regarded as a prerequisite for $\mathrm{SCM}$, as manifested in high levels of external integration. Nonetheless, the desirability of achieving seamless integration is not something which is unique to SCM. Organisations have long realised the need for company-wide approaches to organisational design and redesign. The development of systems engineering approaches to manufacturing system redesign in the 1970s and 1980s was followed by the focus on organisational re-engineering, often based on business processes, in the 1980s and 1990s (Hammer \& Champy, 1993). A common feature of these approaches was recognition that 'the whole is greater than the sum of the parts'. In other words, optimising subsystems (whether those subsystems are functional departments, production sites or individual processes in the manufacturing cycle) can result in a suboptimised total system. Lack of efficiency and/ or effectiveness is often a result of the poorly designed interfaces between subsystems rather than any inherent subsystem weaknesses. There are numerous examples of companies which have generated significant improvements in competitive advantage as a result of the application of this 'total systems' thinking, most especially in the automotive and consumer electronics sectors.

However, a study by Ellinger (2000) recognises that despite its well documented advantages the extent of internal integration is limited. His study, which focused specifically on integration between logistics and marketing functions, concludes that "marketing/logistics interdepartmental relations are only moderately effective" (p. 93).

\section{External Chain Integration}

Every product or service is delivered to the final consumer (the only source of 'real' money in the chain) through a series of often complex movements between companies which comprise the complete chain. An inefficiency anywhere in the chain will result in the chain as a whole failing to achieve its true competitive potential. In other words, supply chains are increasingly competing with other supply chains rather than, in the more traditional axiom, companies 
Figure 4. The internal supply chain

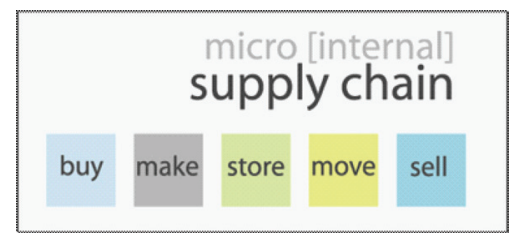

simply competing with other companies. The phrase 'supply chain' is used to indicate that the chain is only as strong as its weakest link. Lambert et al. (1998) suggested that "much friction, and thus waste of valuable resources results when supply chains are not integrated, appropriately streamlined and managed". (p. 14). This concept of inter-company 'friction' is useful in conceptualising the need to replace fragmentation with integration.

The simplistic representation in Figure 5 of the external (or macro- or inter-firm) supply chain shows materials flowing from the raw material source through the various stages in the chain to the final consumer. Money (i.e. funds) then flows back down the chain. The point is that every link matters and that value is added, and profit generated, at each link along the way.

This aspect of Fundamental Two is central to most of the definitions of SCM in the extant literature. As Houlihan (1988) notes, the supply chain is viewed as a single process. In other words, the various links in the chain need to function in as seamless a manner as possible. Monczka et al. (1998) refer to the use of a total systems perspective across 'multiple functions' and 'multiple tiers of suppliers'. The reference to 'multiple functions' alludes to internal integration; extending this to 'multiple tiers of suppliers' introduces the external integration concept, albeit in the rather limited sense of backward integration with suppliers. As noted earlier, the theoretical ideal might be regarded as complete backward and forward integration ('from the supplier's supplier to the customer's customer').

It is important to note that the representation in Figure 5 corresponds to the 'chain level' in the classification of Harland et al. (1999). In reality most 'chains' are more like the 'network level' with multiple suppliers and customers across the various tiers in the 'chain'. Lambert et al. (1998) made reference to:

- Horizontal structure - this refers to the number of tiers across the supply chain.

- Vertical structure-this refers to the number of suppliers/customers represented within each tier.

- Horizontal position - this refers to where the focal company is positioned within the chain (e.g. close to the initial source of supply or nearer to the ultimate customer).

Thus, most 'supply chains' are in reality networks of organisations. In view of this, Lambert and Cooper (2000) suggest that "the ultimate success of the single business will depend on management's ability to integrate the company's intricate network of business relationships" (p. 65).

Complete backward and forward integration, as postulated by Fawcett and Magnan (2002), might be viewed as the theoretical ideal. However, in reality various degrees of integration between upstream and downstream organisations will exist. In this context, Frohlich and Westbrook (2001) proposed the concepts of 'arcs of integration' (Figure 6).

The direction of the segment refers to the direction of integration (i.e. upstream or downstream) while the degree of the arc indicates the level or extent of integration (from "no integration' to 'extensive integration'). Similarly, Bask and Juga (2001) proposed the concept of 'semi-integrated' supply chains. They suggest that "a fully integrated supply 
Figure 5. The external supply chain

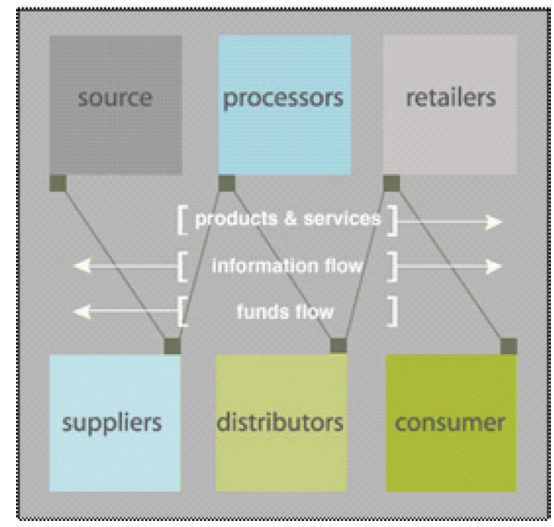

Figure 6. Arcs of integration. Source: based on Frohlich and Westbrook (2001, p.187).

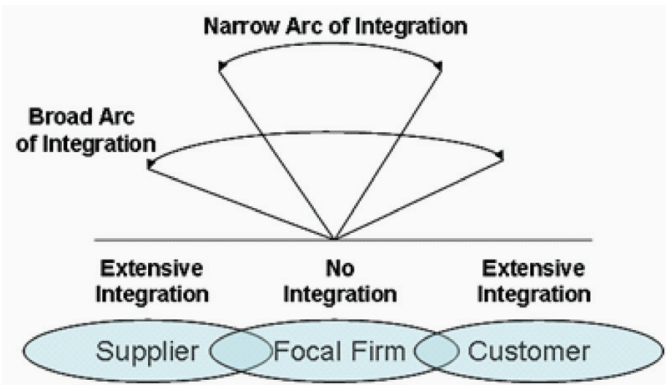

chain sounds impressive but says little" (p. 150). By way of illustration they note that:

The relationships between organisations are subtle and complex and no one recipe exists on how the supply chains achieve best performance. For some companies, tight integration is the answer under regimes like efficient consumer response, quick response, etc. For others, intensive integration may be the goal in selected areas of SCM, while in other areas it can be beneficial to strive for limited integration. Simultaneous properties of tight and lose control are needed as is suggested in the notion of semi-integrated supply chains. (p. 149)

The work ofFabbe-Costes and Jahre (2007) is in line with this concept. They identify a 'dif- ferentiated' approach to supply chain integration which "can help companies to identify and then to focus on a limited number of integration factors" (p. 847).

\section{Fundamental Two: Summary and Some Concluding Points}

Virtually all contemporary definitions place a strong emphasis on the need for a shift from traditional supply chain architectures, which were often characterised by fragmentation, to more effective configurations, which need to replace fragmentation with integration. This is true both in relation to internal and external chains. Fundamental Two recognises this fact. The achievement of high levels of integration has implications for the design of organisa- 
tional structures and supply chain architectures. Kemppainen and Vepsalainen (2003) suggest that in the future this is "expected to result in a new structure of demand-supply networks, in this paper called the encapsulated network, with shared technology and systems, extended decision rights and non-territorial services" ( $p$. 716). Lee (2004) expands on this thinking in his 'Triple-A' concept. This highlights the importance of agility, adaptability and alignment in supply chains if competitive advantage is to be achieved. 'Leading edge' companies may well have adopted this philosophy to varying degrees but there is a need to understand its role and impact in the wider business community. For example, the recent work of Fabbe-Costes and Jahre (2008) concludes that:

In going behind the rhetoric of 'integration is always best', we have shown that 'evidence' cannot be taken for granted and that much more research is needed in particular with regard to the impact of extended inter-organisational SCI on supply chain performance (p. 145).

Finally, moving from fragmented to more integrated approaches inevitably requires changes to the ways in which both internal and external customer and supplier relationships are created and managed (see Fundamental Four).

\section{FUNDAMENTAL THREE: MANAGING THE FLOWS}

\section{Supply Chain Flows}

Forrester's pioneering article from over half a century ago (Forrester, 1958) established a specific link between corporate success and the interactions between five flow systems:

- Information.

- Materials.

- Money.

- Manpower.

- Capital equipment.
Since then, the concept of different flows interacting with each other, and the need to proactively manage these flows, is a theme which has been the subject of much research and discussion.

In essence, for a supply chain to achieve its maximum level of effectiveness and efficiency, material flows, money flows and information flows throughout the entire chain must be managed in an integrated and holistic manner, driven by the overall service and financial objectives.

It is worth noting that Forrester (1958) alluded to five flows (manpower and capital equipment being the additional two). Croom et al. (2000) also referred to five flows (knowledge and technology being the additional two). In a sense, knowledge flow could be regarded as the $21^{\text {st }}$ Century incarnation of manpower flows (knowledge flow being a consequence of interaction between people) and technology flow the $21^{\text {st }}$ Century incarnation of capital equipment flows. In the context of defining the essence of SCM, however, the exchanges focused upon are the material, money and information flows, as these are viewed as being the critical elements of supply chain operations planning and control.

The view of an external chain shown in Figure 5 indicates the way in which material, money (funds) and information flow between the companies which participate in the chain. Similar flows typically occur between the functions which comprise the internal chain. The following sections provide an overview of some of the issues involved in managing these material, money, and information flows, with a particular emphasis on the latter.

\section{Managing Material Flows}

Figure 5 shows the flow of material ('products and services' from the source of materials forward (or upstream) to the final consumer in the external chain. It should be noted that there is also a backward (or downstream) flow of materials, mainly associated with product returns. The growing importance of reverse logistics in recent years has sharpened the focus on management of these flows. For example, 'Return' is 
the process most recently incorporated into the SCOR model (Supply Chain Council, 2010).

Much SCM theory has its origins in the well-established field of materials management. The evolution of materials management in many ways mirrors the evolution of SCM as a whole. For example, the focus on manufacturing inventory reduction in the 1960s and 1970s became an integral part of the broader field of materials management in the 1980s and early 1990s (Battaglia, 1994). The need for more integrated approaches to materials management across the supply chain became a strong focus in the 1990s (Sweeney, 2007). It could be argued that the whole field of logistics, with its origins in a military context, is fundamentally concerned with the efficient and effective management of the flow of materials through supply chains. In any event, ensuring that the right materials are in the right part of the supply chain at the right times, remains an integral element of the SCM field.

\section{Managing Money Flows}

In a supply chain, money flows from the ultimate consumer of the product back down through the chain. The timing of these flows is critical to ensuring that supply chain companies maintain the ability to meet their ongoing operational expenditure commitments. The working capital cycle - a well-known construct in the field of financial management - provides a useful representation of financial flows in a supply chain (Figure 7).

A performance metric used within the SCOR model is 'cash-to-cash cycle time' (Supply Chain Council, 2010). This is defined by adding the number of day's worth of inventory held to the number of days of receivables outstanding and then subtracting the number of days of payables outstanding. The result is a measure of the number of days of working capital that are tied up in managing the supply chain. However, it is interesting to note that many of the widelt cited SCM definitions, including that of the CSCMP discussed earlier, make no reference to the management of money flows as an integral SCM activity.

\section{Managing Information Flows}

As shown in Figure 5 information flows in the supply chain are bidirectional. From an SCM perspective, it can be argued that managing the information flows is the most critical of the activities described in this section. This is because the flow or movement of materials or money is usually triggered by an associated information movement. Effective management of material and money flows is, therefore, predicated upon the effective management of the related information flows. It is not surprising, therefore, that recent years have seen a huge interest in this area in the literature (Lee et al., 1997; Auramo et al., 2005). The bullwhip effect to which Forrester (1958) referred is essentially the product of poor information management in the supply chain and leads to a requirement to hold excessive levels of inventory. The corollary of this is that if levels of demand visibility are high throughout the supply chain then inventory levels can be reduced. As Christopher (2005) notes, good information effectively becomes a substitute for high levels of inventory. Simatupang et al. (2002) illustrate the importance of effective information management using the example of WalMart. WalMart shares point of sales data (for example, sales and stocking data) with key suppliers, which enables these suppliers to, for example, differentiate popular from slowmoving items and to respond appropriately. This coordination "dramatically increases product availability and reduces inventory costs" (Simatupang et al., 2002, p. 289). In this way the twin SCM objectives (Fundamental One) of improved customer service (in the form of increased product availability) and optimised costs (in the form of reduced inventory costs) are achieved. 


\section{Fundamental Three: Summary and Some Concluding Points}

Fundamental Three provides the key to putting the philosophy of SCM, as outlined in Fundamental Two, into operational practice. It highlights the specific activities that need to take place, and places a strong emphasis on the need for an integrated and holistic approach to their management. A stepwise decomposition of the buy-make-store-move-sell model, as carried out in the SCOR model, identifies in more detail what these activities are and how they interact. Indeed, most of the activities typically seen by companies as being part of SCM relate to the planning and control of these elements of supply chain functionality (Fawcett \& Magnan, 2002). In this context, 'planning and control' is concerned with material, money and information throughout the supply chain.

\section{FUNDAMENTAL FOUR: RELATIONSHIP MANAGEMENT}

\section{Supply Chain Relationships}

The need to replace fragmentation with integration (as advocated in Fundamental Two) and the holistic approach to flow management (as advocated in Fundamental Three) requires a re-appraisal of the way in which both internal and external customer/supplier relationships are created and managed. As noted by Sweeney (2007), SCM is not a 'zero-sum' game based on adversarial relationships. Rather, it needs to be a 'win-win' game based on partnership approaches. This point is relevant to the interactions between the key internal supply chain functions of buy, make, store, move and sell, as well as to relationships between an organisation and its external customers and suppliers. In other words, if the concept of integration is a central tenet of SCM philosophy then the management of relationships can be regarded as a key mechanism in ensuring that this philosophy is put into practice. Several of the SCM definitions in the literature highlight the importance of relationship management. For example, the
CSCMPdefinition(CSCMP, 2010) specifically embraces the concept of "co-ordination and collaboration with channel partners".

Croom et al. (2000) identify ten variables which influence the nature of relationships between actors in a network. These include the attitude and commitment to collaborative improvement programmes, legal issues and the degree of power and influence of each party. It is widely recognised that, as noted by Lambert and Cooper (2000), "the closeness of the relationship at different points in the supply chain will differ" (p. 69). In other words, it is not a case of 'one size fits all'. A key management decision involves determination of the appropriate relationship that best suits a particular set of circumstances.

\section{The Impact of Vertical Disintegration}

As companies increasingly focus on what they regard as their core activities or competencies. The corollary of this is that activities regarded as 'non-core' are being outsourced. Key supply chain activities such as transportation, warehousing and manufacturing are increasingly being outsourced to third-party organisations. This has resulted in a shift away from the traditional model of 'control through ownership' towards models which are based on management and control through effective supply chain relationship management (Christopher, 2005). In short, as this process of vertical disintegration has taken place so supply chain architectures have become more virtual. Amore virtual supply chain architecture is one in which a wider range of organisations are integrally involved in the fulfillment of ultimate customer requirements.

\section{Fundamental Four: Summary and Some Concluding Points}

Based on the foregoing, the creation and management of partnerships with all customers and suppliers (internally and externally) is not what Fundamental Four is about. As stated earlier, it is about recognising that putting SCM philosophy into practice requires a reappraisal 
Figure 7. The working capital cycle

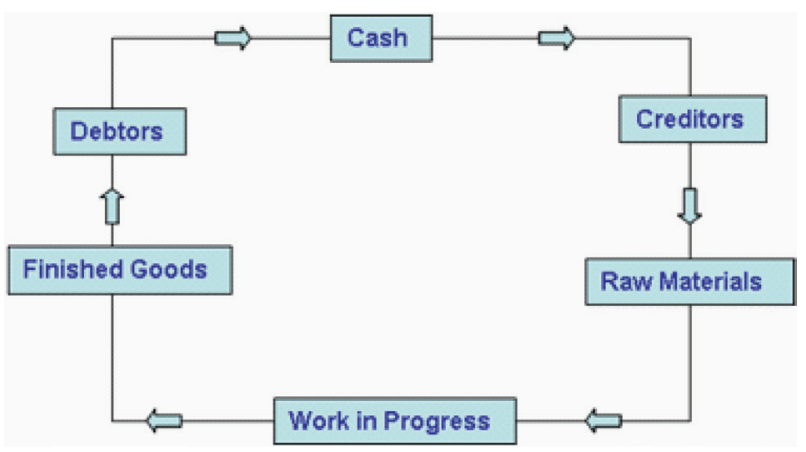

of such relationships. There is no 'one size fits all' approach to this. There are many possible relationship forms (e.g. full partnership, partial alliance, long-term contract) and choosing the right ones in specific situations is the key. Nonetheless, one of the biggest manifestations of the application of SCM in recent years has involved the move away from adversarial relationships with key external suppliers towards relationships which are based on mutual trust and benefits, openness and shared goals and objectives. For example, Harland et al. (1999) highlighted the shift away from multi-sourced adversarial trading with suppliers, towards single or dual sourcing, resulting in a reduction (or 'rationalisation') of supplier bases used by firms.

\section{CONCLUSION}

There is a growing recognition that firms cannot achieve their true competitive potential by operating in isolation. The philosophy of SCM is based firmly on a recognition that it is only by working in a more integrated manner that competitive advantage can be maximised. However, for this to become a reality the development of common definitions and understandings between supply chain partners is a critical success factor. The corollary of this is that a lack of definitional consistency and a common understanding is an inhibitor to the successful adoption of SCM thinking in practice. By addressing this issue, a stronger basis is created to facilitate the collaborative approaches necessary for the improvement of overall supply chain capability and performance. The author believes that the Four Fundamentals concisely, yet comprehensively, define the essence of SCM, as it has evolved from a variety of disciplines over time.

In a similar vein, Mentzer et al. (2001) made the point that without a clear understanding of SCM, wide application of SCM in practice cannot be expected. Furthermore, and as noted earlier, Ross (1998) suggested that the complicated terminology often used in discussions of SCM can limit management's understanding and its effectiveness for practical application. The Four Fundamentals, developed through a process of induction from a range of literature, aid the development of such an understanding. Further work is needed to empirically test the validity of this construct in a variety of business contexts and settings. This work should adopt a multi-paradigmatic philosophical approach and methodological pluralism to ensure that as wide a range of perspectives as possible are explored. The author's ongoing work is using focused interviews and focus groups to further refine the construct, as well as large scale surveys of SCM practice to deductively test the construct. 


\section{REFERENCES}

Auramo, J., Kauremaa, J., \& Tanskanen, K. (2005). Benefits of IT in supply chain management: An explorative study of progressive companies. International Journal of Physical Distribution \& Logistics Management, 35(2), 82-100. doi:10.1108/09600030510590282

Bask, A. H., \& Juga, J. (2001). Semi-integrated supply chains: Towards the new era of supply chain management. International Journal of Logistics: Research and Applications, 4(2), 137-152. doi:10.1080/13675560110059434

Battaglia, A. J. (1994). Beyond logistics: Supply chain management (operations). Chief Executive, $99,48-50$.

Bechtel, C., \& Jayaram, J. (1997). Supply chain management: A strategic perspective. International Journal of Logistics Management, 8(1), 15-34. doi:10.1108/09574099710805565

Bowersox, D. J., Closs, D. J., \& Stank, T. P. (2000). Ten mega-trends that will revolutionize supply chain logistics. Journal of Business Logistics, 21(2), 1-16.

Burgess, K., Singh, P. K., \& Koroglu, R. (2006). Supply chain management: Astructured literature review and implications for future research. International Journal of Operations \& Production Management, 26(7), 703-729. doi:10.1108/01443570610672202

Christopher, M. (1992). Logistics and supply chain management: Strategies for reducing costs and improving services. London, UK: Financial Times/ Pitman.

Christopher, M. (2005). Logistics and supply chain management: Creating value adding networks (3rd ed.). Harlow, UK: FT Prentice Hall.

Christopher, M., \& Towill, D. R. (2000). Supply chain migration from lean and functional to agile and customised. Supply Chain Management: An International Journal, 5(4), 206-213. doi:10.1108/13598540010347334

Cousins, P. D., Lawson, B., \& Squire, B. (2006). Supply chain management: Theory and practice-the emergence of an academic discipline? International Journal of Operations \& Production Management, 26(7), 697-702. doi:10.1108/01443570610672194

Croom, S., Romano, P., \& Giannakis, M. (2000). Supply chain management: An analytical framework for critical literature review. European Journal of Purchasing and Supply Management, 6(1), 67-83. doi:10.1016/S0969-7012(99)00030-1
CSCMP. (2010). Council of supply chain management professionals. Retrieved from http://www. cscmp.org

Ellinger, A. E. (2000). Improving marketing/logistics cross-functional collaboration in the supply chain. Industrial Marketing Management, 29, 1-6. doi:10.1016/S0019-8501(99)00114-5

Fabbe-Costes, N., \& Jahre, M. (2007). Supply chain integration gives better performance - the emperor's new suit? International Journal of Physical Distribution \& Logistics Management, 37(10), 835-855. doi:10.1108/09600030710848941

Fabbe-Costes, N., \& Jahre, M. (2008). Supply chain integration and performance:Areview of the evidence. International Journal of Logistics Management, 19(2), 130-154. doi:10.1108/09574090810895933

Fawcett, S. E., \& Magnan, G. M. (2002). The rhetoric and reality of supply chain integration. International Journal of Physical Distribution \& Logistics Management, 32(5), 339-361. doi:10.1108/09600030210436222

Forrester, J. W. (1958). Industrial dynamics: A major breakthrough for decision makers. Harvard Business Review, 36, 37-66.

Frohlich, M. T., \& Westbrook, R. (2001). Arcs of integration: An international study of supply chain strategies. Journal of Operations Management, 19(2), 185-200. doi:10.1016/S0272-6963(00)00055-3

Grant, D. B. (2004). UK and US management styles in logistics: Different strokes for different folks? International Journal of Logistics: Research and Applications, 7(3), 181-197.

Hammer, M., \& Champy, J. M. (1993). Reengineering the corporation: A manifesto for business revolution. London, UK: Allen and Urwin.

Harland, C. M., Lamming, R. C., \& Cousins, P. D. (1999). Developing the concept of supply strategy. International Journal of Operations \& Production Management, 19(7), 650-673. doi:10.1108/01443579910278910

Juga, J. (2003). Case study research in logistics. In Ojala, L., \& Hilmola, O. P. (Eds.), Turku school of economics and business administration, series $B$. Turku, Finland: Turku School of Economics and Business Administration.

Kathawala, Y., \& Abdou, K. (2003). Supply chain evaluation in the service industry: A framework development compared to manufacturing. Managerial Auditing Journal, 18(2), 140-149. doi:10.1108/02686900310455137 
Kemppainen, K., \& Vepsalainen, A. P. J. (2003). Trends in industrial supply chains and networks. International Journal of Physical Distribution \& Logistics Management, 33(8), 701-719. doi:10.1108/09600030310502885

Korpela, J., Lehmusvaara, A., \& Tuominen, M. (2001). Customer service based design of the supply chain. International Journal of Production Economics, 69(2), 192-204. doi:10.1016/S09255273(00)00062-1

La Londe, B. J. (1994). Evolution of the integrated logistics concept. In Robeson, J., \& Capacino, W. (Eds.), The logistics handbook (pp.3-12). New York, NY: Free Press.

La Londe, B. J., \& Pohlen, T. L. (1996). Issues in supply chain costing. International Journal of Logistics Management, 7(1), 1-12. doi:10.1108/09574099610805395

La Londe, B. J., \& Zinzer, P. H. (1976). Customer service: Meaning and measurement. Chicago, IL: National Council of Physical Distribution Management.

Lambert, D. M. (2004). Supply chain management . In Lambert, D. M. (Ed.), Supply chain management: Processes, partnerships, performance (pp. 1-23). Sarasota, FL: Supply Chain Management Institute.

Lambert, D. M., \& Cooper, M. C. (2000). Issues in supply chain management. Industrial Marketing Management, 29(1), 65-83. doi:10.1016/S00198501(99)00113-3

Lambert, D. M., Cooper, M. C., \& Pagh, J. D. (1998). Supply chain management: Implementation issues and research opportunities. International Journal of Logistics Management, 9(2), 1-19. doi:10.1108/09574099810805807

Lee, H. L. (2004). The triple-a supply chain. Harvard Business Review, 102-112.

Lee, H. L., Padmanabhan, V., \& Whang, S. (1997). Information distortion in a supply chain: The bullwhip effect. Management Science, 43(4), 546-558. doi: $10.1287 / \mathrm{mnsc} .43 .4 .546$

Mentzer, J. T., DeWitt, W., Keebler, J. S., Min, S., Nix, N. W., \& Smith, C. D. (2001). Defining supply chain management. Journal of Business Logistics, 22(2), 1-25. doi:10.1002/j.2158-1592.2001.tb00001.x

National Institute for Transport and Logistics. (2001). Customer service: Technical fact sheet. Dublin, Ireland: NITL.
New, S. J. (1997). The scope of supply chain management research. Supply Chain Management: An International Journal, 2(1), 15-22. doi:10.1108/13598549710156321

New, S. J., \& Payne, P. (1995). Research frameworks in logistics: Three models, seven dinners and a survey. International Journal of Physical Distribution \& Logistics Management, 25(10), 60-77. doi:10.1108/09600039510147663

Oliver, R. K., \& Webber, M. D. (1992). Supply-chain management: Logistics catches up with strategy. In Christopher, M. (Ed.), Logistics: The strategic issues (pp. 63-75). London, UK: Chapman \& Hall.

Pagell, M. (2004). Understanding the factors that enable and inhibit the integration of operations, purchasing and logistics. Journal of Operations Management, 22(5), 459-487. doi:10.1016/j. jom.2004.05.008

Porter, M. E. (1985). Competitive advantage: Creating and sustaining superior performance. New York, NY: Free Press.

Ross, D. F. (1998). Competing through supply chain management. New York, NY: Chapman \& Hall.

Saunders, M. J. (1995, March). Chains, pipelines, networks and value stream: the role, nature and value of such metaphors in forming perceptions of the task of purchasing and supply management. In Proceedings of the First Worldwide Research Symposium on Purchasing, Tempe, AZ (pp. 476-485).

Simatupang, T. M., Wright, A. C., \& Sridharan, R. (2002). The knowledge of coordination for supply chain integration. Business Process Management Journal, 8(3), 289-308. doi:10.1108/14637150210428989

Sterling, J. U., \& Lambert, D. M. (1989). Customer service research: Past, present and future. International Journal of Physical Distribution and Logistics Management, 19(2), 2-23. doi:10.1108/ EUM0000000000306

Storey, J., Emberson, C., Godsell, J., \& Harrison, A. (2006). Supply chain management: Theory, practice and future challenge. International Journal of Operations \& Production Management, 26(7), 754-774. doi: $10.1108 / 01443570610672220$

Supply Chain Council. (2010). Welcome to Supply Chain Council. Retrieved from http://www.supplychain.org 
Sweeney, E. (2007). Perspectives on supply chain management and logistics: Creating competitive organisations in the $21^{\text {st }}$ century. Dublin, Ireland: Blackhall Publishing.

Sweeney, E., Wagner, C., \& Huber, B. (2008). Supply chain management diffusion among firms in the Republic of Ireland. International Journal of Logistics: Research and Applications, 11(4), 347-358. doi:10.1080/13675560802389122
Tan, K. C. (2001). A framework of supply chain management literature. European Journal of Purchasing and Supply Management, 7(1), 39-48. doi:10.1016/ S0969-7012(00)00020-4

Edward Sweeney is Director of Learning at the National Institute for Transport and Logistics (NITL), based at the Dublin Institute of Technology (DIT). He has held full-time academic posts at the University of Warwick (UK) and the University of Technology, Malaysia, as well as visiting positions in several Asian universities and institutes. Edward is an engineer by background and has worked and lectured in over 30 countries in Europe, North America and Asia. He is an experienced researcher with over 200 publications including books and book chapters, papers in international peer-reviewed academic journals, practitioner journal articles and conference papers. His recent publications include papers in the International Journal of Logistics: Research and Applications and Supply Chain Management: an International Journal. The focus of his current work is on resilience and sustainability in global supply chains. 